method of avoiding outbreaks of CPE gastroenteritis is safe food handling.

\section{Public health control measures}

The immediate control of outbreaks of gastroenteritis in an institution is important to prevent the spread of infection to other residents, staff and visitors. In 2005, a toolkit titled 'Gastro Pack' was developed that provides information on the early recognition of an outbreak, implementation of control measures, management of affected people and communication strategies. ${ }^{8}$ The Department of Health and Ageing have released a similar resource titled 'Gastro Info Kit', designed specifically for outbreaks in aged-care facilities. ${ }^{9}$ Use of these guidelines should aid in the containment of gastroenteritis outbreaks in institutions.

\section{References}

1. NSW Department of Health, Communicable Diseases Branch. Gastroenteritis Outbreaks in Institutions Database. (Cited 5 November 2009.)

2. Cretikos M, Telfer B, McAnulty J. Enteric disease outbreak reporting, New South Wales, Australia, 2000 to 2005. N S W Public Health Bull 2008; 19(1-2): 3-7. doi:10.1071/NB07078
3. The OzFoodNet Working Group. Monitoring the incidence and causes of diseases potentially transmitted by food in Australia: annual report of the OzFoodNet Network, 2007. Commun Dis Intell 2008; 32(4): 400-24.

4. Riley TV. Clostridium difficile: a pathogen of the nineties. Eur J Clin Microbiol Infect Dis 1998; 17(3): 137-41.

5. Estes MK, Verkataram Prasad BV, Atmara RL. Noroviruses everywhere: has something changed? Curr Opin Infect Dis 2006; 19: 467-74. doi:10.1097/01.qco.0000244053.69253.3d

6. Smedley JG, 3rd, Fisher DJ, Sayeed S, Chakrabarti G, McClane BA. The enteric toxins of Clostridium perfringens. Rev Physiol Biochem Pharmacol 2004; 152: 183-204. doi:10.1007/s10254004-0036-2

7. Young MK, Smith P, Holloway J, Davison RP. An outbreak of Clostridium perfringens and the enforcement of food safety standards. Commun Dis Intell 2008; 32: 462-5.

8. NSW Department of Health. Gastro Pack. Available from: http://www.health.nsw.gov.au/resources/publichealth/ infectious/diseases/gastro_pack_pdf.asp (Cited 6 September 2009.)

9. Department of Health and Ageing. Gastro-Info - Outbreak Coordinator's Handbook. Available from: http://www.health. gov.au/internet/main/publishing.nsf/Content/ageing-publicatgastro-kit-handbook.htm (Cited 6 September 2009.)

\title{
Genital Chlamydia trachomatis infection
}

\author{
Evan Freeman $^{\mathrm{A}}$, Basil Donovan ${ }^{\mathrm{B}, \mathrm{C}}$ \\ and Katherine Brown ${ }^{\mathrm{D}, \mathrm{E}}$ \\ ${ }^{\mathrm{A}} N S W$ Public Health Officer Training Program, \\ NSW Department of Health \\ ${ }^{\mathrm{B}}$ National Centre in HIV Epidemiology and \\ Clinical Research, The University of New South Wales \\ ${ }^{\mathrm{C}}$ The Sydney Sexual Health Centre, Sydney Hospital \\ ${ }^{D}$ South Eastern Sydney Illawarra Area Health Service \\ ${ }^{\mathrm{E}}$ The University of Wollongong
}

Chlamydia trachomatis is one of three species of Chlamydiae that commonly cause disease in humans. It is responsible for ano-genital and conjunctival (conjunctivitis and trachoma) infections. Infant conjunctivitis and pneumonia can result from maternal genital infection. ${ }^{1}$ C. trachomatis serovars D-K are responsible for most sexually-acquired genital infections. Serovar $\mathrm{L}_{2}$ causes a severe proctolitis or genital ulcer lymphadenopathy syndrome known as lymphogranuloma venereum which is beginning to reappear in Australia among men who have sex with men. ${ }^{2}$
Chlamydia is a notifiable condition in New South Wales (NSW) under the Public Health Act 1991. There were 14947 laboratory-confirmed cases notified in 2009. Known as the 'silent disease', it is the most reported sexually transmissible infection (STI) in Australia, the United States, the United Kingdom and Canada. Due to the mainly asymptomatic nature of chlamydia, chronic infection and re-infection are common, ${ }^{3}$ highlighting the importance of screening. ${ }^{4}$ People aged less than 25 years have the highest rates of infection.

\section{Symptoms}

Most infected people are asymptomatic ( $70 \%$ of women and $90 \%$ of men). Symptoms that may occur during acute infections include urethral discharge and discomfort on urination (dysuria). Men may also develop painful swollen testes (epididymitis). Women occasionally report dysuria or bleeding between periods. Deep pain during sexual intercourse and lower abdominal pain in women suggest pelvic inflammatory disease from ascending infection. Pelvic inflammatory disease increases the risk of subsequent 
ectopic pregnancy and infertility. ${ }^{3}$ Either gender can develop reactive arthritis, associated with mucocutaneous lesions.

\section{Testing}

Ano-genital tract infection can be detected using selfcollected vaginal or anal swabs or a urine specimen. Self-collected specimens have lowered the barriers to testing. A clinician may collect a cervical swab if a woman has symptoms or as part of a pap test. A variety of nucleic acid amplification tests are also used, with sensitivities in the range of $85-97 \%$ and specificities exceeding $99 \%$.

\section{Treatment}

Uncomplicated ano-genital infection is treated with a single oral dose of azithromycin. ${ }^{1}$ Complicated infections (pelvic inflammatory disease and epididymitis) and lymphogranuloma venereum require treatment with doxycycline for a minimum of 14 days; other antibiotics are also often required. ${ }^{5}$

\section{Re-infection and contact tracing}

While cure rates are high (>95\%), re-infection rates are also high (approximately 30\%). Therefore, people treated for chlamydia should be retested after 12 weeks of treatment. As infected sexual partners are typically asymptomatic, they often do not present for contact testing and treatment. The value and legality of dispensing a second dose of azithromycin for the patient to deliver to their partner(s) (patient-delivered partner therapy) has been recommended for review in Australia. ${ }^{6}$

\section{The Australian Collaboration for Chlamydia Enhanced Sentinel Surveillance (ACCESS) Project} The Commonwealth-funded ACCESS Project has been established in response to increasing numbers of chlamydia notifications, with the possibility that much of the increase could be due to increased testing. ${ }^{7}$ Priority populations requiring ongoing surveillance include Aboriginal and Torres Strait Islanders, young heterosexuals, men who have sex with men, and sex workers. An early impression determined through this pilot sentinel surveillance is that rates of chlamydia may not be rising as quickly as the notification data suggest.
Fast-track treatment: using patient-delivered partner therapy to reduce chlamydia prevalence Patient-delivered partner therapy has been considered because of the increasing number of diagnoses and the concern that current clinical treatment systems are not slowing the spread of disease. This process includes the patient providing advice to their partner about the nature of chlamydial infection, testing and treatment.

It is believed to work best when clients are selected; avoiding high-risk populations where other STIs and bloodborne viruses may be of concern (e.g. injecting drug users and men who have sex with men). The Centers for Disease Control and Prevention in the United States has included this option within its current guidelines for STI management.

\section{References}

1. Heymann DL, editor. Control of Communicable Diseases Manual. 19th ed. Washington: American Public Health Association; 2008.

2. Stark D, van Hal S, Hillman R, Harkness J, Marriott D. Lymphogranuloma venereum in Australia: anorectal Chlamydia trachomatis serovar L2b in men who have sex with men. $J$ Clin Microbiol 2007; 45(3): 1029-31. doi:10.1128/JCM.02389-06

3. Cretikos M, Davies S, Brotherton A. Chlamydia, gonorrhoea and syphilis. NS W Public Health Bull 2006; 17(5-6): 86-7.

4. Geisler WM, Wang C, Morrison SG, Black CM, Bandea CI, Hook EW, 3rd. The natural history of untreated Chlamydia trachomatis infection in the interval between screening and returning for treatment. Sex Transm Dis 2008; 35(2): 119-23. doi:10.1097/OLQ.0b013e318151497d

5. Centers for Disease Control and Prevention. Updated recommended treatment regimens for gonococcal infections and associated conditions - United States, April 2007. Available from: http://www.cdc.gov/std/treatment/2006/updatedregimens.htm (Cited 1 February 2010.)

6. McNulty A, Teh MF, Freedman E. Patient delivered partner therapy for chlamydial infection-what would be missed? Sex Transm Dis 2008; 35(9): 834-6. doi:10.1097/ OLQ.0b013e3181761993

7. Chen MY, Fairley CK, Donovan B. Nowhere near the point of diminishing returns: correlations between chlamydia testing and notification rates in New South Wales. Aust N Z J Public Health 2005; 29(3): 249-53. doi:10.1111/j.1467-842X.2005.tb00763.x 